\title{
Robert Bendavid (and E. Acquaviva)
}

\author{
M. Soler ${ }^{1} \cdot$ J. Giuly ${ }^{2}$
}

๑) Springer-Verlag France SAS, part of Springer Nature 2019

Robert Bendavid passed away on 30 September and was buried on 3 October 2019. John Morrison, a close friend of Robert Bendavid, announced the bad news this 2 October during the APHS Congress in Bali. I met Robert Bendavid for the first time 30 years ago in Amiens at the annual meeting organised by my mentor René Stoppa. And the last time I spoke to him was in Hambourg on September 13th: he could not go to the EHS meeting and he stayed in his hotel because he was so tired. We had talked at breakfast about several topics and particularly about our work on Eugene Acquaviva, a French surgeon from Marseille. This was then, among other things, one of his last concerns. As confirmed by John Morrison, Robert Bendavid used to evoke Acquaviva quite often during conversations.

Eugene Acquaviva was the first designer and user of a synthetic prosthesis in parietal surgery (first publication in 1944). René Stoppa had mentioned this little-known information in his book "Hernia Healers" (1998) [1] which tells the history of the treatment of hernias since ancient times ... This had aroused the curiosity of the late Robert Bendavid who suspected that Acquaviva might have had a crucial role in the emergence of this kind of prosthetic parietal surgery and wished to reveal the forgotten historical elements on such issues that are still actual to the community of surgeons. Since I live near Marseille, several years ago he had asked me to search the archives on this subject. And with the decisive help of Jules Giuly, surgeon in Marseille, we were surprised to discover the Acquaviva's work of the early 1940s concerning the design and the use of a synthetic material in parietal surgery.

Thanks to R. Couture, a chemical engineer who helped him design a nylon trellis called crinoplaque, E. Acquaviva

M. Soler

soler.marc2@wanadoo.fr

$\triangle$ J. Giuly

giulyjules@wanadoo.fr

1 Parietal Surgery Department, Saint-Jean Clinic, Cagnes-sur-Mer, France

2 Marseille, France became the true pioneer in the use of a parietal reinforcement prosthesis. Under the patronage of R. Bendavid, an article was thus being written. Robert Bendavid had an incredible culture about hernia surgery and he was still so curious about everything around the abdominal surgery. In particular, upon the request of René Stoppa, he translated the works of the famous Henri Fruchaud: Anatomie chirurgicale des hernies de l'aine (1956); The Surgical Anatomy of Hernias of the Groin (2006). Fruchaud's work was only published in French and had not had the legitimate repercussion at the time. His books are currently permanently cited thanks to the English translation.

We have now lots of very interesting details about the early age of abdominal wall prosthetics, i.e. the 1940s. With our research, we will continue to disseminate, the incredible innovative ideas of $\mathrm{E}$. Acquaviva about the prosthetic materials.

The surgeons of my generation thought that modern ideas on prostheses dated back to the 1970s, a little more than a decade after F.C. Usher had started working with Marlex. However, E. Acquaviva had already mentioned many problems (e.g. infection, no touch procedure, overlapping, shrinking, histocompatibility, position of the mesh in the abdominal wall and not in the intraabdominal cavity, etc.) nearly 30 years before.

After the death of Robert Bendavid, my thoughts go to the pioneers of parietal surgery, firstly my mentor R. Stoppa, then his close friend G. Wantz, as well as J. Rives, L. M. Nyhus and G. Trivellini among the others.

Dear Robert Bendavid, I promise that we will soon finish our work and make it known to our colleagues about the contribution of Don Eugene Acquaviva to parietal surgery.

RIP

\section{References}

1. Stoppa R, Wantz GE, Munegato G, Pluchinetta A (1998) Hernias healers. An illustrated history. Arnette, Velizy Villacoubley

Publisher's Note Springer Nature remains neutral with regard to jurisdictional claims in published maps and institutional affiliations. 